\title{
Squamous Cell Carcinoma Arising in Recurrent Respiratory Papillomatosis with Pulmonary Involvement: Emerging Common Pattern of Clinical Features and Human Papillomavirus Serotype Association
}

James R. Cook, M.D., Ph.D., D. Ashley Hill, M.D., Peter A. Humphrey, M.D., Ph.D., John D. Pfeifer, M.D., Ph.D., Samir K. El-Mofty, D.M.D., Ph.D.

Lauren V. Ackerman Laboratory of Surgical Pathology, Department of Pathology, Washington University School of Medicine, St. Louis, Missouri

\begin{abstract}
Squamous papillomas of the lung are an uncommon feature of recurrent respiratory papillomatosis, occurring in fewer than $1 \%$ of cases. We describe a 23-year-old patient with pulmonary papillomas who developed a fatal squamous cell carcinoma of the lung. PCR-based human papillomavirus (HPV) typing showed the presence of HPV 11 DNA in both benign papillomas and invasive carcinoma. A review of the literature reveals four reports of malignant transformation of juvenile-onset recurrent respiratory papillomatosis in which HPV typing was performed. Similar clinical features are noted in all of the reports; specifically, each case has arisen in a young adult man with a history of papillomatosis since childhood. In each of the cases, HPV 11 was identified in association with the squamous cell carcinoma. Although HPV 11 is uncommonly associated with the development of invasive carcinoma at other sites, these findings suggest that it is correlated with malignant transformation in the setting of juvenile-onset recurrent respiratory papillomatosis.
\end{abstract}

KEY WORDS: Human papillomavirus 11, Recurrent respiratory papillomatosis, Squamous cell carcinoma. Mod Pathol 2000;13(8):914-918

Juvenile-onset recurrent respiratory papillomatosis (RRP) is characterized by numerous squamous papillomas of the respiratory tract secondary to infection with human papillomavirus (HPV) types 6 and $11(1,2)$. HPV is thought to be acquired at the time

Copyright (C) 2000 by The United States and Canadian Academy of Pathology, Inc.

VOL. 13, NO. 8, P. 914, 2000 Printed in the U.S.A.

Date of acceptance: February 11, 2000.

Address reprint requests to: James R. Cook, M.D., Ph.D., Division of Surgical Pathology, Box 8118, Barnes-Jewish Hospital, 660 South Euclid Avenue, St.

Louis, MO 63110; e-mail: jcook@path.wustl.edu; fax: 314-362-8950. of vaginal delivery in the presence of genital lesions, and patients typically present with symptoms of hoarseness or respiratory obstruction in childhood or adolescence. In the majority of cases, the papillomas are confined to the larynx; only $5 \%$ of patients exhibit more distal involvement of the trachea, and involvement of lung parenchyma occurs in fewer than $1 \%$ of cases $(1,2)$.

Pulmonary involvement by RRP is twice as frequent in males than in females and is associated with an aggressive clinical course. Most patients require numerous excisions, frequently require tracheostomy, and ultimately die as a result of respiratory insufficiency or infections (2). Malignant transformation of laryngeal or pulmonary lesions is a very rare event in the absence of prior irradiation; fewer than 20 cases are reported in the English literature (3-6). It remains unclear whether the risk of malignant transformation is dependent on the HPV serotype involved.

We describe a patient with pulmonary involvement by RRP who developed a squamous cell carcinoma of the lung. Polymerase chain reaction (PCR) typing performed at postmortem examination showed the presence of HPV 11 DNA in both the papillomas and squamous cell carcinoma. This is the fifth report of an association between HPV 11 and malignant transformation of pulmonary papillomas $(3,4,6,7)$. Together, these five cases suggest a stereotypical clinical setting for the emergence of invasive carcinoma from RRP.

\section{CASE REPORT}

The patient was a 23-year-old white man with a history of RRP, initially diagnosed at age 5. By age 10 , he had developed laryngeal, tracheal, and pulmonary papillomas. He underwent more than 100 surgical excisions and laser ablations, required 
multiple tracheotomies for tracheal obstruction, and was frequently treated for postobstructive pneumonia and pulmonary abscesses. He was also treated with interferon- $\alpha$, acyclovir, indol-3carbanol, and an adjunctive trial of measles vaccine injection. Clinical response was noted only to therapy with interferon- $\alpha$, which reduced the bulk of his papillomas and the frequency of required surgical interventions. During late adolescence and into young adulthood, the patient smoked approximately one half to one pack of cigarettes per day $(<10$ pack-year history total).

At age 22, the patient began to complain of weight loss and thoracic pain radiating to the scapula. Chest radiographs demonstrated an enlarging right upper lobe mass, and a bronchial washing showed invasive squamous cell carcinoma. He was treated with radiotherapy for control of pain and local control of the tumor. Subsequent chest radiographs demonstrated continuing enlargement of the mass, which seemed to compress the right main bronchus. He experienced progressive respiratory compromise and died approximately 1 year after the diagnosis of carcinoma.

\section{MATERIALS AND METHODS}

\section{DNA Extraction}

Five, $10-\mu$ sections of formalin-fixed, paraffinembedded tissue obtained at autopsy were deparaffinized using xylene and ethanol washes and were digested overnight at $65^{\circ} \mathrm{C}$ in digestion buffer (Tris pH 7.5, 20 mm EDTA, 1\% SDS) containing 200 $\mu \mathrm{g} / \mu \mathrm{L}$ proteinase K. Samples were boiled with Chelex 100 resin for $20 \mathrm{~min}$ and centrifuged, the aqueous phase was transferred to a new tube, and DNA was quantitated by spectrophotometry.

\section{PCR Amplification}

PCR analysis was carried out using the GeneAmp kit (Perkin-Elmer, Foster City, CA) with HPV consensus primers as described by Manos et al. (8): MY09-CGTCCMARRGGAWACTGATC; MY11-GCMCAGGGWCATAAYAATGG where $\mathrm{R}=\mathrm{A}+\mathrm{G}, \mathrm{W}=\mathrm{A}+\mathrm{T}$, $\mathrm{M}=\mathrm{A}+\mathrm{C}$, and $\mathrm{Y}=\mathrm{C}+\mathrm{T}$. As a control for intact amplifiable DNA, primers for the $\beta$-globin gene were also used in the same reaction: globinl-ACACAACTGTGTTCACTAGC; globin2-CAACTTCATCCACGTTCACC. Reactions were carried out in $50-\mu \mathrm{L}$ volumes with $0.5 \mu \mathrm{M}$ primers and $2 \mathrm{mM} \mathrm{MgCl}_{2}$. The reaction parameters were as follows: initial denaturation at $95^{\circ} \mathrm{C}$ for $5 \mathrm{~min}$; 35 cycles each at $95^{\circ} \mathrm{C}$ for $1 \mathrm{~min}, 50^{\circ} \mathrm{C}$ for $1 \mathrm{~min}$, and $72^{\circ} \mathrm{C}$ for $1 \mathrm{~min}$; final extension at $72^{\circ} \mathrm{C}$ for $5 \mathrm{~min}$.

\section{DNA Sequencing}

PCR products were cloned into vector pCR2.1 using the TA cloning kit (Invitrogen, Carlsbad, CA) and sequenced using the Taq DyeDeoxy terminator cycle sequencing kit (Applied Biosystems Inc., Foster City, CA) and an automated fluorescent DNA sequencer (Model 373A; Applied Biosystems Inc.). DNA sequence analysis was facilitated by BLAST sequence similarity searches using the National Center for Biotechnology Information database (http://www.ncbi.nlm.nih.gov/BLAST/).

\section{RESULTS}

\section{Autopsy Findings}

Postmortem examination was limited to the lungs, larynx, trachea, thyroid, and a portion of vertebral bone. Examination of the larynx and trachea revealed numerous papillomas, ranging in diameter from less than 0.1 to $0.4 \mathrm{~cm}$, extending from the larynx to the level of the carina. Several of the papillomas showed mild to moderate dysplasia (Fig. 1A, B). The right and left mainstem bronchi did not contain papillomas. The lungs were firm and heavy (1450 g, combined weight). Both lungs were involved by numerous cavitary papillomas, ranging from 0.1 to $1.5 \mathrm{~cm}$ in diameter. The pulmonary papillomas consisted of squamous epithelium with underlying nests of squamous cells within alveolar spaces (Fig. 1C, D). A rim of compressed uninvolved parenchyma in turn surrounded these areas. The squamous nests were distinguished from an invasive carcinoma by the presence of intact alveolar septa, low-grade cytology, a pushing border, and the absence of desmoplasia.

The pleura of the right lung was thickened by fibrosis, ranging from 0.2 to $0.5 \mathrm{~cm}$ in thickness. A $4.5-\mathrm{cm}$ firm, partially necrotic, well-differentiated squamous cell carcinoma was present in the right upper lobe that encircled but did not invade the right mainstem bronchus (Fig. 2). The carcinoma
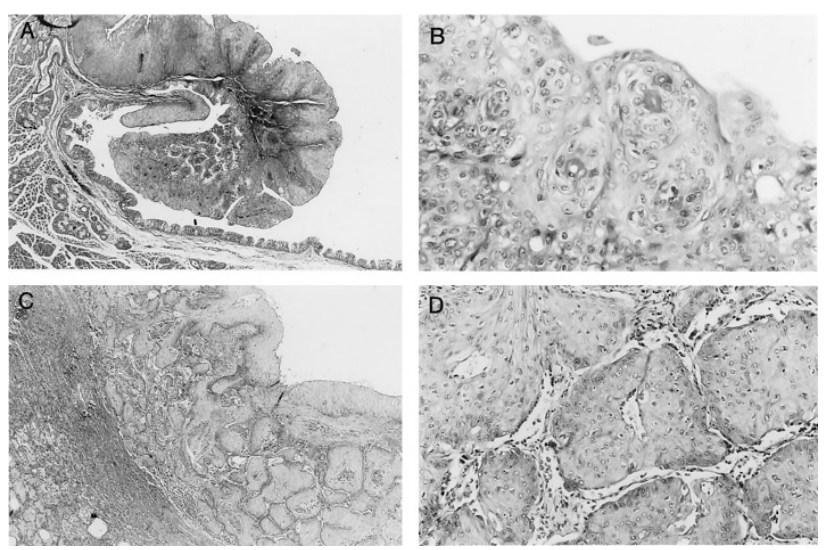

FIGURE 1. Sections of the larynx and trachea showing numerous squamous papillomas with mild nuclear pleomorphism (A and $\mathbf{B})$. The lung contained cavitary papillomas lined by squamous epithelium (C) with underlying nests of noninvasive squamous cells within intact alveolar spaces (D). 

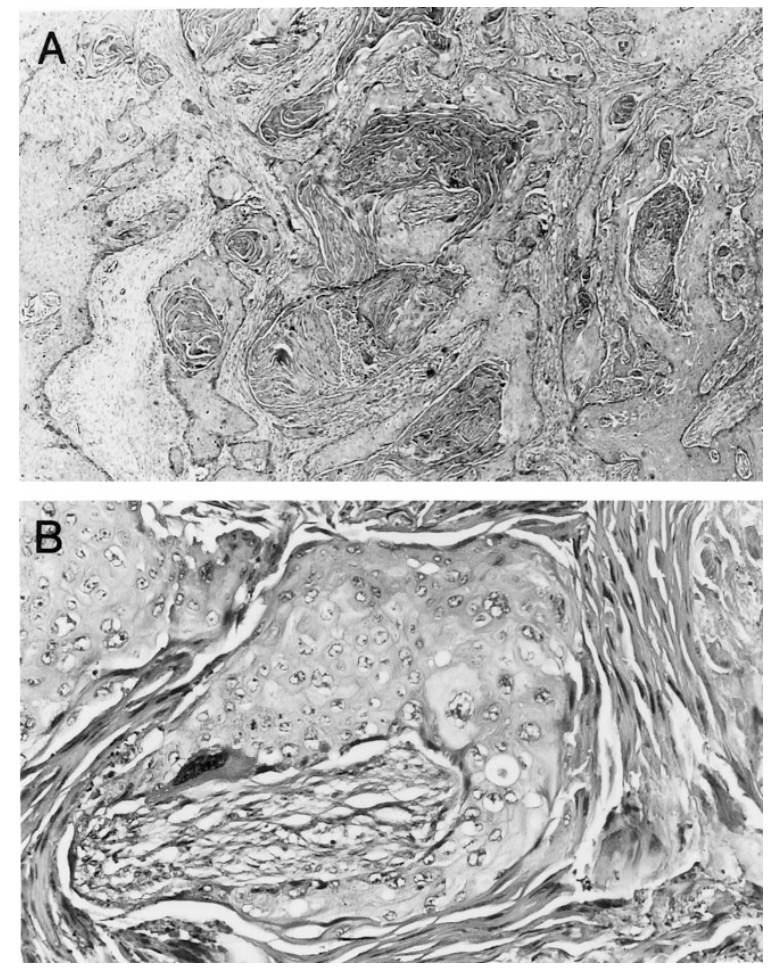

FIGURE 2. The right upper lobe contained a $4.5-\mathrm{cm}$ invasive, welldifferentiated squamous cell carcinoma (A) with marked nuclear pleomorphism (B).

consisted of irregular, invasive tongues of keratinizing squamous cells with moderate to severe cytologic atypia. In contrast to the pulmonary squamous papillomas, the carcinoma was associated with a marked desmoplastic reaction and showed invasive destruction of surrounding alveolar parenchyma. Examination of hilar and peribronchial lymph nodes showed no evidence of metastatic disease. Foci of acute bronchopneumonia were also identified in sections of the right lung. The sections of thyroid and vertebral bone showed no evidence of metastatic carcinoma.

\section{PCR-Based HPV Typing}

To evaluate the association of the patient's carcinoma with HPV, DNA was extracted from sections of carcinoma, laryngeal papillomas, and, as a negative control, thyroid. A preparation of purified genomic HPV 16 DNA was used as a positive control. HPV DNA was detected in the patient's carcinoma and papillomas, as indicated by the presence of the expected $450 \mathrm{bp}$ band, but HPV DNA was not detected in the preparation of thyroid DNA (Fig. 3). The expected band was also amplified from the control preparation of purified HPV 16 DNA (data not shown). Sequence analysis of the amplified products demonstrated HPV serotype 11 in both the papillomas and carcinoma and confirmed that the control HPV DNA was serotype 16, as expected.

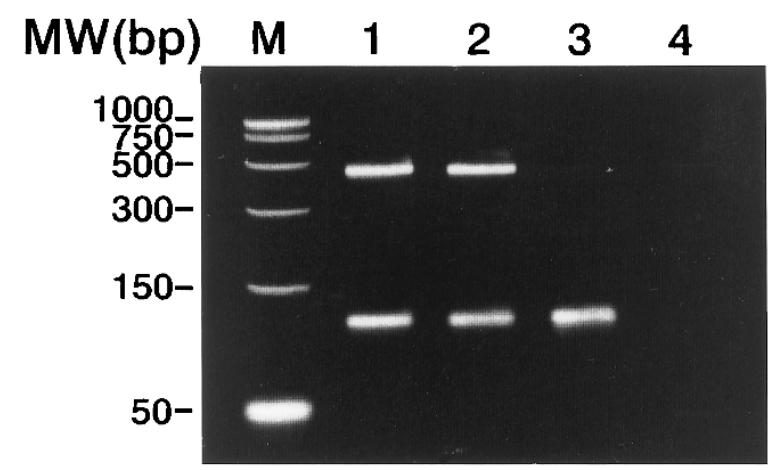

FIGURE 3. Polymerase chain reaction analysis for the presence of human papillomavirus DNA (450 bp) and human $\beta$-globin (107 bp). Human papillomavirus DNA is detected in the invasive squamous cell carcinoma and laryngeal papillomas, but not in thyroid. $\beta$-globin was amplified from each tissue, as expected. Lane M, molecular weight markers; Lane 1, invasive squamous cell carcinoma; Lane 2, laryngeal papilloma; Lane 3, thyroid; Lane 4, water (omitted DNA template) control.

\section{DISCUSSION}

In this article, we describe a patient with RRP with pulmonary involvement who developed welldifferentiated squamous cell carcinoma of the lung approximately 17 years after the onset of papillomatosis. HPV 11 DNA was detected in both benign papillomas and squamous cell carcinoma. Numerous studies have examined the HPV serotypes associated with RRP and have identified HPV 6 and 11 as the causative agents both in cases limited to the larynx (9) and in cases with involvement of the lung $(1,10,11)$. The frequency of individual HPV serotypes in juvenile-onset papillomas has been reported as 50 to $84 \%$ for HPV 6 and 25 to $37 \%$ for HPV $11(12,13)$. However, a review of the literature reveals only four case reports of squamous cell carcinoma of the lung arising in the setting of pulmonary papillomatosis in which HPV typing was performed (Table 1). Comparison of the reported cases shows a common pattern of clinical features. As in our case, all of the patients described were men, with onset of RRP in early childhood (range, infancy to 5 years) and development of carcinoma in the third or fourth decade of life. Two of the patients had a history of tobacco use. None had been treated with irradiation before the diagnosis of carcinoma. HPV typing in each case showed HPV 11 DNA associated with the squamous cell carcinoma. The consistent finding of HPV 11 DNA is unlikely to represent simply the prevalence of this serotype in benign precursor lesions because HPV 6 has been detected in RRP even more frequently than HPV 11 (as discussed above).

Epidemiologic data have shown that HPV 11 is not among the specific HPV serotypes that are associated with malignant transformation, the socalled "high risk" or oncogenic HPV types (14). Nonetheless, malignant transformation of lesions 
TABLE 1. Reported Cases of HPV-Associated Squamous Cell Carcinoma of the Lung in Pulmonary Recurrent Respiratory Papillomatosis

\begin{tabular}{|c|c|c|c|c|c|c|}
\hline Source & Sex & Onset (y) & $\begin{array}{c}\text { Death } \\
(y)\end{array}$ & $\begin{array}{c}\text { Tobacco } \\
\text { Use }\end{array}$ & Irradiation & $\begin{array}{c}\text { HPV } \\
\text { Serotype }\end{array}$ \\
\hline Byrne et al., 1987 (7) & $\mathrm{M}$ & Infancy & 27 & No & No & 11 \\
\hline Lindeberg et al., 1989 (4) & $\mathrm{M}$ & 3 & 21 & Yes & No & 11 \\
\hline Guillou et al., 1991 (3) & $\mathrm{M}$ & 2 & 35 & No & No & 11 \\
\hline Rady et al., 1998 (6) & $\mathrm{M}$ & Childhood & 28 & No & No & 11 \\
\hline This report & $\mathrm{M}$ & 5 & 23 & Yes & No & 11 \\
\hline
\end{tabular}

HPV, human papillomavirus.

caused by HPV 11 does occur, although it is an infrequent occurrence $(15,16)$. DNA sequence analysis has shown that specific viral mutations are associated with malignant transformation, demonstrating the role of specific viral genes in oncogenesis (17). The increased frequency of detection of HPV 11 in tumors from immunocompromised patients indicates that host factors also influence the process of carcinogenesis (17). In this context, the demonstration of mutations in host genes (specifically, allelic loss of the interferon- $\beta$ gene and mutation of p53) associated with malignant transformation in a case of RRP (6) is provocative. However, the precise mechanism by which host mutations may contribute to malignant transformation in RRP is unknown, as is the role of viral mutations.

Genetic differences between HPV 11 and HPV 6 that could account for the skewing of the association between malignant transformation and HPV type in the setting of RRP are unknown. It is interesting that DiLorenzo et al. (5) reported a case of HPV type 6a-associated lung carcinoma arising in a patient with laryngeal papillomatosis. The authors did not comment, however, on prior irradiation therapy or the presence of pulmonary papillomas. It is therefore unclear whether their case represents malignant transformation of a pulmonary papilloma or an isolated lung lesion in a patient with disease limited to the larynx.

In contrast to juvenile-onset RRP, adult-onset papillomatosis shows a greater tendency to be solitary and is less likely to be associated with HPV 6 or $11(18,19)$. It has also been reported in adult-onset papillomatosis that HPV is more frequently detected in laryngeal carcinomas than in dysplastic, noninvasive laryngeal papillomas, suggesting that HPV plays a later role in carcinogenesis in adultonset cases than in juvenile-onset cases (15). HPV typing was performed in two cases of malignant transformation of adult-onset laryngeal papillomatosis. In these cases, squamous cell carcinomas of the larynx were found to be associated with HPV 6 (18) or HPV 18 (20). Review of the literature shows no reported cases of malignant change of a pulmonary papilloma in the setting of adult-onset papillomatosis. Taken together, these differences in clinical presentation between juvenile-onset and adult- onset RRP suggest that they may represent distinct clinical entities with differences in pathogenesis reflecting the association with different HPV serotypes.

In summary, we have demonstrated the association of HPV 11 with a squamous cell carcinoma of the lung arising in the setting of juvenile-onset RRP with pulmonary spread. Further studies on a larger series of patients are necessary to assess the relative risk of malignant transformation associated with various HPV types and to confirm that HPV 11 represents a "high risk" lesion in this clinical setting. Such information may prove to be of prognostic significance for patients with RRP.

Acknowledgments: We thank Dr. Janet Rader for the generous gift of purified HPV 16 DNA and Dr. Xiaopei Zhu for expert technical assistance.

\section{REFERENCES}

1. Kramer S, Wehunt W, Stocker JT, Kashima H. Pulmonary manifestations of juvenile laryngotracheal papillomatosis. AJR Am J Roentgenol 1985;144:687-94.

2. Magid M, Chen YT, Soslow R, Boulad F, Kernan N, Szabolcs P. Juvenile-onset recurrent respiratory papillomatosis involving the lung: a case report and review of the literature. Pediatr Dev Pathol 1998;1:157-63.

3. Guillou L, Sahli R, Chaubert P, Monnier P, Cuttat JF, Costa J. Squamous cell carcinoma of the lung in a nonsmoking, nonirradiated patient with juvenile laryngotracheal papillomatosis: evidence of human papillomavirus-11 DNA in both carcinoma and papillomas. Am J Surg Pathol 1991;15:891-8.

4. Lindeberg H, Syrjanen S, Karja J, Syrjanen K. Human papillomavirus type 11 DNA in squamous cell carcinomas and pre-existing multiple laryngeal papillomas. Acta Otolaryngol 1989;107:141-9.

5. DiLorenzo R, Tamsen A, Abramson A, Steinberg B. Human papillomavirus type 6a DNA in the lung carcinoma of a patient with recurrent laryngeal papillomatosis is characterized by a partial duplication. J Gen Virol 1992;73:423-8.

6. Rady P, Schnadig V, Weiss R, Hughes T, Tyring S. Malignant transformation of recurrent respiratory papillomatosis associated with integrated human papillomavirus type 11 DNA and mutation of p53. Laryngoscope 1998;108:735-40.

7. Byrne J, Tsao MS, Fraser R, Howley P. Human papillomavirus-11 DNA in a patient with chronic laryngotracheobronchial papillomatosis and metastatic squamous-cell carcinoma of the lung. N Engl J Med 1987;317:873-8.

8. Manos M, Ting Y, Wright D, Lewis A, Broker T, Wolinsky S. The use of polymerase chain reaction amplification for the 
detection of genital human papillomaviruses. Cancer Cells 1989;7:209-14.

9. Steinberg B. Human papillomaviruses and upper airway oncogenesis. Am J Otolaryngol 1990;11:370-4.

10. Mounts P, Shah K, Kashima H. Viral etiology of juvenile- and adult-onset squamous papilloma of the larynx. Proc Natl Acad Sci U S A 1982;79:5425-9.

11. Corbitt G, Pzarod A, Arrand J, Longson M, Farrington W. Human papillomavirus (HPV) genotypes associated with laryngeal papilloma. J Clin Pathol 1988;41:284-8.

12. Garcia-Milian R, Hernandez H, Panade L, Rodriguez C, Gonzalez N, Valenzuela C, et al. Detection and typing of human papillomavirus DNA in benign and malignant tumours of laryngeal epithelium. Acta Otolaryngol (Stockh) 1998;118:754-8.

13. Mounts P, Kashima H. Association of human papillomavirus subtype and clinical course in respiratory papillomatosis. Laryngoscope 1984;94:28-33.

14. zur Hausen H. Papillomaviruses in human cancer. Cancer 1987;59:1692-6.

15. Gorgoulis V, Zacharatos P, Kotsinas A, Kyroudi A, Rassidakis A, Ikonomopoulos J, et al. Human papilloma virus (HPV) is possibly involved in laryngeal but not in lung carcinogenesis. Hum Pathol 1999;30:274-83.

16. Gissmann L, Wolnik L, Ikenberg H, Koldovsky U, Schnurch HG, zur Hausen H. Human papillomavirus types 6 and 11 DNA sequences in genital and laryngeal papillomas and in some cervical cancers. Proc Natl Acad Sci U S A 1983;80: $560-3$.

17. McGlennen R, Ghai J, Ostrow R, LaBresh K, Schneider J, Faras A. Cellular transformation by a unique isolate of human papillomavirus type 11. Cancer Res 1992;52:5872-8.

18. Zarod A, Rutherford J, Corbitt G. Malignant progression of laryngeal papilloma associated with human papilloma virus type 6 (HPV-6) DNA. J Clin Pathol 1988;41:280-3.

19. Terry R, Lewis F, Robertson S, Blythe D, Wells M. Juvenile and adult laryngeal papillomata: classification by in-situ hybridization for human papillomavirus. Clin Otolaryngol 1989;14:135-9.

20. Sakakura A, Yamamoto Y, Takasaki T, Makimoto K, Nakamura M, Takahashi H. Recurrent laryngeal papillomatosis developing into laryngeal carcinoma with human papilloma virus (HPV) type 18: a case report. J Laryngol Otol 1996;110: $75-7$. 